\title{
Application of response surface methodology in process parameters optimization for phenol mineralization using Fenton's peroxidation
}

\author{
Diya'uddeen Basheer Hasan, A. R. Abdul Aziz and Wan Mohd Ashri Wan Daud* \\ Chemical Engineering Department, Faculty of Engineering, Universiti Malaya, Malaysia.
}

Accepted 21 March, 2011

\begin{abstract}
Adverse effect of the highly biorecalcitrant compound phenol to the environment is well established and its concentrations in industrial effluents vary greatly from 2.8 to $6,800 \mathrm{mg} / \mathrm{l}$ depending on the source. Fenton process effectively mineralises to $\mathrm{CO}_{2}$ and $\mathrm{H}_{2} \mathrm{O}$ but reported works consumed more reagents and require longer reaction times. Due to the strong interaction between the several predictor variables in the Fenton oxidation, response surface methodology was used to optimise the mineralization treatment. Efficient, faster and economical operating conditions for phenol removal were explored by investigating four parameters namely the concentration ratio of hydrogen peroxide to phenol - $\left(\left(\mathrm{H}_{2} \mathrm{O}_{2}\right)\right.$ : $($ Phenol $\left.)\right)$, mass ratio of hydrogen peroxide to ferrous ions - $\left(\left(\mathrm{H}_{2} \mathrm{O}_{2}\right):\left(\mathrm{Fe}^{2+}\right)\right)$, initial phenol concentration - $\left([\mathrm{Phenol}]_{\mathrm{o}}\right)$ and reaction time - $\left(\mathrm{t}_{\mathrm{r}}\right)$. The optimal TOC \% reduction obtained were 35 and $88 \%$ for initial phenol concentrations of 100 and $5 \mathrm{mg} / \mathrm{l}$, respectively. Reaction conditions corresponding to this phenol mineralization a reaction time of $20 \mathrm{~min}$ at ratios of 6 and 15 for $\left[\mathrm{H}_{2} \mathrm{O}_{2}\right]$ : $[\mathrm{Phenol}]$ and $\left[\mathrm{H}_{2} \mathrm{O}_{2}\right]:\left[\mathrm{Fe}^{2+}\right]$, respectively. For mineralisation at $52.5 \mathrm{mg} / \mathrm{l}$ phenol concentration, the optimal conditions were $20 \mathrm{~min}$, ratios 10 and 15 for the reaction time, $\left[\mathrm{H}_{2} \mathrm{O}_{2}\right]:[\mathrm{Phenol}]$ and $\left[\mathrm{H}_{2} \mathrm{O}_{2}\right]:\left[\mathrm{Fe}^{2+}\right]$, respectively. The soluble iron content of the analysed supernatant was found to be below the $15 \mathrm{mg} / \mathrm{l}$ (the maximum limit allowable for total iron discharges required by common regulative subscribed). This indicated that, the Fenton reagents were utilised during the peroxidation reaction evident from the almost near consumption of all $\mathrm{Fe}^{2+}$ introduced in about $85 \%$ of the samples, thus, negating the need for immobilising the $\mathrm{Fe}^{2+}$ catalyst or its removal by post treatment. The work proves that the optimized Fenton process can be potentially used for treatment of any phenol containing wastewater.
\end{abstract}

Key words: Fenton process, phenol mineralization, response surface methodology.

\section{INTRODUCTION}

Environmental pollution control continues to receive great attention due to negative impact for ecosystems and humans from industrial effluents. These discharges are toxic, carcinogenic and with mutagenic properties (Busca et al., 2008). Presently, $42 \%$ of the global wastewater generation trace their origin to process industries (Doan

${ }^{*}$ Corresponding author. E-mail: ashri@um.edu.my. Tel: +603 70675297. Fax: +603 70675319.

Abbreviations: TOC, Total organic carbon; COD, comparatively values of degradation; CCD, central composite design; OVAT, one variable at a time. et al., 2009) and one of the components found in organic wastewater that attracts significant environmental concern is phenol. It is most abundant (lurascu et al., 2009) with a wide range of application as raw material in many industries whose operations are associated with generation of large amounts of wastewater, for example, chemical, petrochemical, pharmaceutical, textile and agricultural industries (Guo and Al-Dahhan, 2005; Yang et al., 2008). Global production of phenol is high mainly in an attempt to augment the ever-high increase in industrial demand for the raw material and recent figures quoted by lurascu et al. (2009) indicate the current annual production to stand now at over three million tons thus, resulting in its presence in many wastewater (lurascu et al., 2009). 
Apart from the toxic effect of phenol to aquatic life, its presence in water is a source of unpleasant odor, gives an off-flavors taste in drinking and food processing waters at concentrations as low as $1 \mathrm{mg} / \mathrm{l}$ (Priya et al., 2008). Phenol's acute toxicity is well-established (lurascu et al., 2009); this made imposition of a more striker limitation to disposal of phenol-containing effluents. Its high oxygen demand, estimated at $2.4 \mathrm{mg} \mathrm{O} / \mathrm{mg}$ of phenol (Priya et al., 2008) depletes the dissolved oxygen content of the receiving waters bodies thus, directly interfering with the natural existence of organisms in the waters. Currently, the Environmental Protection Agency (EPA) has set less than 1 part per billion (ppb) of phenol in surface waters, $0.5 \mu \mathrm{g} / \mathrm{l}$ in potable and mineral waters, while the limits for wastewater discharges are $0.5 \mathrm{mg} / \mathrm{l}$ for surface waters and $1 \mathrm{mg} / \mathrm{l}$ for the sewerage system (Busca et al., 2008).

The most common wastewater treatment is the biological treatment (Gernjak et al., 2003). However, phenol being highly stable, toxic, soluble in water, refractory coupled with its non-biodegradable nature makes its treatments less effective due to the inhibition and even elimination of the abundant bacteriological populations in municipal wastewater treatment (Guo and Al-Dahhan, 2005; Hong et al., 2001). Above a concentration of $200 \mathrm{mg} / \mathrm{l}$, the process treatment is not attractive due to the difficulty in treatment and longer time requirements (Kavitha and Palanivelu 2004). Such high decomposition times have been reported for example, 40 and $340 \mathrm{~h}$ by Prieto et al. (2002) and Gonzalez et al. (2001), respectively, in their biological treatment of phenol at a 200 and $1000 \mathrm{mg} / \mathrm{l}$.

The slow rate of reaction in biological systems has been attributed to the larger space requirement and higher sludge formation (Wei et al., 2003). Others are either phase transfer techniques (adsorption), partially degrade, (biological or expensive) and membrane technology. The serious adverse effects and stringent regulations on discharge of phenol containing wastewater necessitate the need for cost effective and robust treatment technologies.

A category of destructive approach is the advanced oxidation processes (AOP's). A technology well established as an efficient and effective means of mineralizing wide range of organic pollutants $(\mathrm{RH})$ and waste streams (Kiril et al., 2010; Gernjak et al., 2003). AOP's are generally characterised by the generation of the extremely reactive hydroxyl radical species that act as an oxidant in the mineralization of complex organic compounds found in wastewater (Chakinala et al., 2008). The most cost efficient and easy to set up process AOP that requires minimal energy input for the hydroxyl radical $\left({ }^{\circ} \mathrm{OH}\right)$ generation is Fenton's process (Kiril et al., 2010). Here, a mixture of $\mathrm{Fe}^{2+}$ or any other ferrous complex and $\mathrm{H}_{2} \mathrm{O}_{2}$ referred to as Fenton's reagent is introduced into the wastewater at sufficiently low $\mathrm{pH}$, the $\mathrm{H}_{2} \mathrm{O}_{2}$ is catalytically decomposed to produce the hydroxyl radical (Mahiroglu et al., 2009; Barros et al., 2006) as follows:

$\mathrm{Fe}^{2+}+\mathrm{H}_{2} \mathrm{O}_{2} \rightarrow \mathrm{Fe}^{3+}+\mathrm{OH}^{-}+{ }^{\circ} \mathrm{OH}$

$\mathrm{RH}+{ }^{\circ} \mathrm{OH} \rightarrow \mathrm{R}^{\circ}+\mathrm{H}_{2} \mathrm{O}$

It is well known that the reaction pathways involving $\cdot \mathrm{OH}$ radicals and the Fenton reactions are very complex and that compounds (and degradation by-products) can play different roles on the overall reaction rates ( $\mathrm{Li}$ et al., 2005; Banerjee and Ghoshal, 2005; Cai et al., 2007; Chen et al., 2008).

In addition, much work using the different AOPs have been published on treatment of phenol, bulk of the research either aimed at providing insight to the reaction pathways/reaction mechanism (Li et al., 2005; Banerjee and Ghoshal, 2005; Cai et al., 2007; Chen et al., 2008; Bach et al., 2010; Pontes et al., 2010) or finding optimum condition of degrading the phenol. On the latter objective, literature on optimising Fenton's process for phenol is scares and optimised condition reported were either based on the one variable at a time (OVAT) approach (Kavitha and Palanivelu, 2004; Kiril et al., 2010), did not account for the role of the Fenton reagent ratios (Kiril et al., 2010; Yalfani et al., 2009) or conducted at a fixed initial phenol concentration (Yalfani et al., 2009; Zazo et al., 2009). An implication is that reaction would finish leaving excess reagent, possible total consumption of the reagents before reaction time finishes or model developed might not be precise at some points within the reactor. Moreover, performance of most chemical reactions in the reactor could be different at different levels of process variables such as the concentrations (Salamatinia et al., 2010). Reported composition ranges of phenol in chemical processes producing phenol differ from source to source (Ahmadi et al., 2005; Moussavi et al., 2010; Busca et al., 2008). However, discharges from phenol-containing effluents in the lower ranges (5 to 100 $\mathrm{mg} / \mathrm{l})$ pose a greater concern and more interest is on their treatment (Yalfani et al., 2009). Against this backdrop, we conducted mineralisation of aqueous phenol solution at concentration ranging between 5 to $100 \mathrm{mg} / \mathrm{l}$.

In this current work, focus was to obtain an empirical equation that would be employed in determining the most suitable operating conditions at various phenol concentrations with the objective of maximising its mineralization efficiency and minimising Fenton's reagent consumption. An empirical model equation that adequately described phenol mineralization by Fenton's process was developed. The suitability of the polynomial model was found to be satisfactory from the ANOVA performed at $95 \%$ confidence level.

\section{MATERIALS AND METHODS}

\section{Stock solutions preparation}

All the stock solutions used in this Fenton peroxidation experiment 
were prepared with ultra pure water from ultra pure water system (arium 611UF, Sartorius Stedim Biotech $\mathrm{GmbH}$ ) and consumed immediately after preparation.

The phenol stock solution was prepared by dissolving ultra pure phenol grade in ultrapure water and working concentrations of 5 , 52.5 and $100 \mathrm{mg} / \mathrm{l}$ were obtained by dilution of the stock solution. A stock solution of $\mathrm{FeSO}_{4} .7 \mathrm{H}_{2} \mathrm{O}$ (as the source of $\mathrm{Fe}^{2+}$ ) was prepared and appropriately diluted to obtain the desired $\mathrm{Fe}^{2+}$ concentration. The $\mathrm{H}_{2} \mathrm{O}_{2}$ (30\%, Merck Chemical Corp.) was used without dilution. Measured $\mathrm{pH}$ of the $\mathrm{FeSO}_{4} .7 \mathrm{H}_{2} \mathrm{O}$ solution was determined to be 5.7 and all the solutions were prepared and used immediately.

\section{Materials}

The reagents used in this study were all analytical grade and used as received without any purification. From Merck Chemical Company, $\mathrm{FeSO}_{4} .7 \mathrm{H}_{2} \mathrm{O}, \mathrm{H}_{2} \mathrm{O}_{2}$ and phenol were purchased and from Fisher Scientific, $\mathrm{NaOH}(50 \% \mathrm{w} / \mathrm{w})$ and $\mathrm{H}_{2} \mathrm{SO}_{4}$ (97\% purity) were obtained.

\section{Experimental procedure}

All the Fenton reaction was performed batch wise at an ambient temperature of $25^{\circ} \mathrm{C}$ in $250 \mathrm{ml}$ Erlenmeyer flasks containing $100 \mathrm{ml}$ of the desired phenol concentration as the total reaction mixture volume. The range of interest in this study was based on an extensive survey of published works and solution $\mathrm{pH}$ was adjusted to 3 using the $\mathrm{H}_{2} \mathrm{SO}_{4}(1 \mathrm{M})$ solution. The Fenton reagents were dosed under constant magnetic stirring to avoid concentration gradient. Desired amounts of $\mathrm{Fe}^{2+}$ in the form of $\mathrm{FeSO}_{4} .7 \mathrm{H}_{2} \mathrm{O}$ solution was added first, the reaction was then, initiated by addition of hydrogen peroxide $\left(\mathrm{H}_{2} \mathrm{O}_{2}\right)$ in varied concentrations that maintained the designed mass ratios of the Fenton reagent. To avoid unnecessary increase in temperature during addition of the $\mathrm{H}_{2} \mathrm{O}_{2}$, the transfer was done slowly as observed by Ahmadi et al. (2005).

At the end of the reaction, $\mathrm{pH}$ of the treated samples were adjusted to 8 with the aqueous solution of $\mathrm{NaOH}$ (1 M, Merck) for further precipitation and simultaneous coagulation of the $\mathrm{Fe}^{3+}$ in a form of $\mathrm{Fe}(\mathrm{OH})_{3}$ for two hours. The supernatant was then filtered through $0.45 \mu \mathrm{m}$ Millipore filter and subjected for analysis.

\section{Analysis}

The solution of $\mathrm{pH}$ was determined with a $\mathrm{pH}$ Laboratory meter 827 (Metrohom) equipped with a $\mathrm{pH}$ combination electrode. Mineralization of the samples were followed by measurement of total organic carbon (TOC) using a combustion/non-dispersive infrared gas analysis method (NDIR) in a Shimadzu TOC-vcN 5000 analyser (Shimadzu, Japan) equipped with an ASI-V auto sampler and a Shimadzu TOC 5050 analyser.

For effluents treated with the Fenton method, the maximum limit is $15 \mathrm{mg} / \mathrm{l}$ for the total iron before direct discharge into the environment as directed by EU's regulation (Benatti et al., 2006). Therefore, concentrations of the total soluble iron ions in the supernatant were determined in inductively coupled plasma optical emission spectroscopy 7000 DV (ICP-OES, Perkin Elmer).

\section{Experimental design, data analysis and process optimization}

Interaction of the variables involved in Fenton's process is strong, thus, use of one variable at a time (OVAT) approach to study and interpret responses in a multivariate system such as the Fenton process is grossly inadequate. The OVAT refers to the approach of investigating several process parameters by keeping one variable constant and others varied. In this method, interactive effects are not accounted and optimal conditions obtained are not representative of the whole process condition. Responses from processes involving several variables cannot be studied without taking account of the strong interaction between the variables; an effective approach to such processes involve conducting a well planned and predetermined set of chosen experiments based on a multivariate design of experiments.

A multivariate approach that utilises a second-degree quadratic polynomial is thus, necessary in order to obtain unbiased responses that would adequately describe the process with a minimum number of experiments. We present the degradation of phenol based on a central composite design (CCD) with two level factorial design with additional experimental referred to as the star point; the latter experiments are introduced for determining the quadratic response surface. Three repetitions at the centre points were done to allow for better prediction of the reproducibility (Kiril et al., 2010). In addition, experiments at the centre points facilitate the determinations of rotatability or orthogonality of the design and ease of fitting the quadratic polynomials with at least one point (Tarley et al., 2009).

Four independent variables were investigated namely initial phenol concentration, the concentration ratio of $\left[\mathrm{H}_{2} \mathrm{O}_{2}\right]$ :[phenol], mass ratio of $\left[\mathrm{H}_{2} \mathrm{O}_{2}\right]:\left[\mathrm{Fe}^{2+}\right]$ and reaction time. However, $\mathrm{pH}$ was not considered as a specific variable due to the several reported literature that established the optimal $\mathrm{pH}$ at about 3 (Hermosilla et al., 2009; Ay et al., 2009; Martins et al., 2005). This was based on limitation of Fenton reagents performance in different $\mathrm{pH}$ media. As summarised by Kiril et al. (2010), increasing $\mathrm{pH}$ value decreases the oxidation potential of the hydroxyl radicals $\left({ }^{\circ} \mathrm{OH}\right)$ and generally, in a basic medium, the oxidation yield is observed to decrease as $\mathrm{Fe}^{3+}$ exists as a precipitate of $\mathrm{Fe}(\mathrm{OH})_{3}$. This again is associated with hindering the reaction between $\mathrm{Fe}^{3+}$ and $\mathrm{H}_{2} \mathrm{O}_{2}$ by the formed $\mathrm{Fe}(\mathrm{OH})_{3}$, thereby limiting the regeneration step of $\mathrm{Fe}^{2+}$. Moreover, the $\mathrm{Fe}(\mathrm{OH})_{3}$ is known to catalyze the decomposition of $\mathrm{H}_{2} \mathrm{O}_{2}$ to $\mathrm{O}_{2}$ and $\mathrm{H}_{2} \mathrm{O}$, thus, decreasing the production of $\bullet \mathrm{OH}$ and retarding the systems performance. On the other hand, at low $\mathrm{pH}, \mathrm{H}_{2} \mathrm{O}_{2}$ is stabilized as $\mathrm{H}_{3} \mathrm{O}_{2}{ }^{+}$, these results in excess $\mathrm{H}^{+}$within the reacting system and favouring the reaction between $\mathrm{OH} \bullet$ and $\mathrm{H}^{+}$. This leads to retarding the regeneration of $\mathrm{Fe}^{2+}$ by reaction of $\mathrm{Fe}^{3+}$ with $\mathrm{H}_{2} \mathrm{O}_{2}$ which is necessary for sustenance of the oxidation reaction. Literature is replete with studies that established optimum $\mathrm{pH}$ in Fenton's process to range between 2.5 and 3.5 (Benatti et al., 2006; lurascu et al., 2009; Kavitha and Palanivelu, 2004; Zazo et al., 2009; Kiril et al., 2010). Thus, in this study initial reaction $\mathrm{pH}$ was fixed at 3 . The mineralization was monitored at three reaction times 20, 100 and $180 \mathrm{~min}$ for the three different phenol concentrations.

The choice of CCD out of the numerous available designs was informed by it is popularity, reliability and its general acceptance as a standard second-order design (Tarley et al., 2009; Virkutyte et al., 2010).

Table 1 shows the experimental design matrix with the real values for the independent variables set at $-1,0$ and +1 for low, medium and high levels, respectively. From the experimental runs performed, mathematical relationship of the response function (y) and influence of the independent variables is express as a general quadratic polynomial model (Equation 3). The regression coefficients obtained by response surface regression analysis were achieved by fitting experimental data to the quadratic model.

$$
y=\beta_{o}+\sum_{i=1}^{k} \beta_{i} x_{i}+\sum_{j} \sum_{<i=2}^{k} \beta_{i j} x_{i} x_{j}+\sum_{i=1}^{k} \beta_{i i} x_{i}{ }^{2}
$$

The regression coefficients for intercept, linear, quadratic and 
Table 1. Experimental and predicted responses with corresponding total iron content for each batch.

\begin{tabular}{|c|c|c|c|c|c|c|c|}
\hline \multirow{2}{*}{ Run } & \multirow{2}{*}{ (Phenol)o (mg/l) } & \multirow{2}{*}{$\left(\mathrm{H}_{2} \mathrm{O}_{2}\right)$ : (Phenol) } & \multirow{2}{*}{$\left(\mathrm{H}_{2} \mathrm{O}_{2}\right):\left(\mathrm{Fe}^{2+}\right)$} & \multirow{2}{*}{$t_{r}(\min )$} & \multicolumn{2}{|c|}{ Responses (\%) } & \multirow{2}{*}{ Total Fe (mg/l) } \\
\hline & & & & & $y_{\text {Exptl }}$ & YPred & \\
\hline 1 & 100.0 & 10 & 25 & 180 & 41.8 & 39.5 & 10.5 \\
\hline 2 & 52.5 & 10 & 15 & 20 & 60.1 & 60.4 & 1.3 \\
\hline 3 & 100.0 & 6 & 15 & 20 & 34.6 & 41.1 & ND \\
\hline 4 & 5.0 & 2 & 5 & 20 & 88.4 & 92.1 & 3.3 \\
\hline 5 & 5.0 & 2 & 25 & 180 & 87.0 & 91.3 & 0.3 \\
\hline 6 & 52.5 & 10 & 5 & 100 & 61.8 & 58.8 & 4.4 \\
\hline 7 & 52.5 & 2 & 5 & 100 & 54.2 & 55.4 & 0.3 \\
\hline 8 & 100.0 & 2 & 5 & 180 & 67.2 & 14.2 & ND \\
\hline 9 & 100.0 & 6 & 25 & 20 & 36.1 & 39.2 & 0.4 \\
\hline 10 & 5.0 & 6 & 15 & 180 & 87.0 & 82.8 & 34.7 \\
\hline 11 & 5.0 & 6 & 15 & 180 & 87.4 & 79.9 & 3.6 \\
\hline 12 & 100.0 & 6 & 5 & 20 & 37.5 & 34.7 & ND \\
\hline 13 & 52.5 & 10 & 5 & 100 & 61.8 & 61.9 & ND \\
\hline 14 & 52.5 & 10 & 25 & 100 & 66.1 & 61.9 & 14.9 \\
\hline 15 & 52.5 & 2 & 25 & 100 & 60.6 & 61.9 & ND \\
\hline 16 & 52.5 & 6 & 15 & 100 & 60.1 & 62.2 & 15.7 \\
\hline 17 & 100.0 & 10 & 5 & 180 & 35.17 & 28.5 & 2.7 \\
\hline 18 & 5.0 & 2 & 5 & 20 & 86.6 & 94.8 & 30.1 \\
\hline 19 & 5.0 & 6 & 15 & 20 & 88.1 & 80.0 & ND \\
\hline 20 & 5.0 & 10 & 25 & 180 & 38.6 & 46.24 & ND \\
\hline 21 & 100 & 2 & 25 & 180 & 13.6 & 16.14 & 1.7 \\
\hline 22 & 5.0 & 2 & 25 & 20 & 85.3 & 81.7 & ND \\
\hline 23 & 52.5 & 6 & 15 & 100 & 59.36 & 61.5 & ND \\
\hline 24 & 5.0 & 6 & 15 & 100 & 86.5 & 85.9 & ND \\
\hline 25 & 100.0 & 2 & 15 & 20 & 14.1 & 7.9 & 45.0 \\
\hline 26 & 100.0 & 10 & 5 & 100 & 33.7 & 32.4 & 0.4 \\
\hline 27 & 52.5 & 10 & 25 & 180 & 63.0 & 63.3 & 0.4 \\
\hline
\end{tabular}

ND, Not detected; $y_{\text {Exptt }}$, experimental responses; $y_{\text {Pred, }}$, predicted responses.

interaction terms are represented by $\beta_{0}, \beta_{i}, \beta_{i i}$ and $\beta_{i j}$, respectively, while the independent variables that affect the response $\dot{y}$ are denoted by $x_{i}, x_{i i}$ and $x_{i j}$. Data generated was analysed, coefficients in the mathematical model predicting the response estimated and analysis of variance (ANOVA) was used for gaining insight into the interaction between the variables affecting the process and the response. Adequacy check was also performed to ascertain the quality of the fit of polynomial expressed in equation 3 using the coefficient of determination $R^{2}$ and $R_{\text {adj. }}^{2}$

\section{RESULTS AND DISCUSSION}

Studies were conducted batch wise according to a statistically designed experimental matrix (Table 1) in order to map the whole region and obtain reaction conditions at which Fenton's reagent consumption is minimal with corresponding low total iron in the treated samples.

The dependent variable of the process was the TOC removal percentage which was approximated using the CCD and represented by Equation (4). $y=99.78-0.65 x_{1}-1.76 x_{2}+0.06 x_{3}-0.01 x_{4}+0.03 x_{1}$ $x_{2}+2.16 \times 10^{-3} x_{1} x_{3}-1.60 x_{1} x_{4}+0.03 x_{2} x_{3}+5.91 x_{2} x_{4}-$ $2.16 \times 10^{-4} x_{3} x_{4}+1.99 \times 10^{-4} x_{1} x_{3} x_{4}+1.37 \times 10^{-3} x_{2} x_{3} x_{4}$

(4)

The independent variables namely [Phenol $]_{0},\left[\mathrm{H}_{2} \mathrm{O}_{2}\right]$ : [Phenol], ], $\left[\mathrm{H}_{2} \mathrm{O}_{2}\right]:\left[\mathrm{Fe}^{2+}\right]$ and $\mathrm{t}_{\mathrm{r}}$, are represented by $x_{1}, x_{2}$, $x_{3}$ and $x_{4}$, respectively. These variables were studied, their effects on the response analysed and the parameters were estimated by the method of least squares. The response surface was then analysed in terms of the fitted surface.

To assert the suitability of the proposed model for navigating the design space in terms of TOC percent removal, a model adequacy test was conducted. In Table 2 , the results of the ANOVA for the proposed model for percent TOC removals are presented. Proper approximation of the true system can only be achieved with a valid model. Thus, model adequacy check is necessary to validate the approximations and ensure that none of the least square regression assumptions are violated 
Table 2. ANOVA results of the quadratic polynomial model for Fenton treatment of synthetic phenol wastewater.

\begin{tabular}{ccccccc}
\hline Response & Source & Sum of squares & Degree of freedom & Mean square & F-ratio & P-value \\
\hline & Model & 15994.57 & 16 & 999.66 & 17.94 & $<0.0001$ \\
& Residual & 557.14 & 10 & 55.71 & & \\
TOC removal (\%) & Lack of fit & 540.59 & 8 & 67.57 & 8.16 & 0.1136 \\
& Pure error & 16.55 & 2 & 8.28 & & \\
& Total & 16551.71 & 26 & & & \\
\hline
\end{tabular}

$R^{2}=0.9663 ; R_{a d j}^{2}=0.9125 ;$ Adq. prec. ratio $=14.672$.

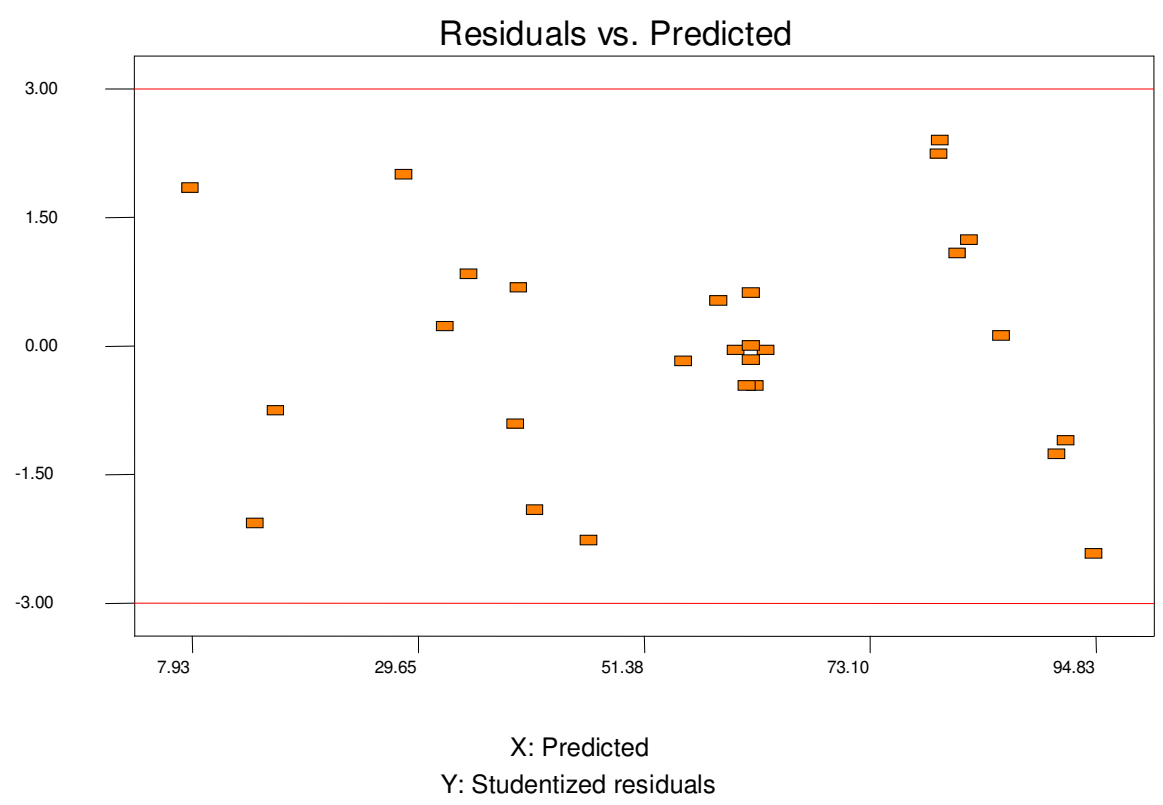

Figure 1. Studentized residuals and initial phenol concentrations plot of the Fenton mineralisation.

(Tekin et al., 2006).

From the ANOVA results (Table 2), the model obtained was significant for the mineralization of the phenol as the TOC removal percent has an F-value of 17.94, implying that there is only a $0.01 \%$ chance that a model F-value this large could occur due to noise. P-values less than 0.05 indicate that, the model is significant whereas greater than 0.10 indicates model not significant; with a value of 0.001 the model adequacy fit is ascertained. A value of 14.672 for the adequate precision signal to noise ratio was derived for the response variable. This value exceeds the minimum desirable value of 4 signifying adequate signal for the TOC removal percent.

From the ANOVA analysis in Table 2, the model could satisfactorily predict the phenol TOC removal percent well. The value of 0.9663 for the correlation coefficient of the model $\left(R^{2}\right)$ indicate that, there is a satisfactory quadratic fit as it implies that $97 \%$ of the total variation in TOC removal reported was adequately represented by the model. Although, $R^{2}$ reasonably predicts model adequately fairly well but having a high value of $R^{2}$ does not necessarily imply a very good prediction. This is associated with the fact that, there exists the possibility of having poor predictions of new observations or estimates of the mean response, thus, a modified form of the $R^{2}$ referred to as $R_{\text {adj }}^{2}$ is employed. Values of $R^{2}$ are always higher than or equal to $R_{a d j}^{2}$ because the $R_{\text {adj }}^{2}$ adjusts the number of explanatory terms in a model thus, it can have a negative value. Merit of the former parameter over the latter is that, while addition of variables to the model always results in an increase in $R^{2}$ value it is significantly not affected in $R^{2}$ adj it is often reported to decrease if unnecessary terms are added. Based on closeness of correlation coefficient values of 0.9663 and 0.9125 for $R^{2}$ and $R_{\text {adj }}^{2}$, respectively, it appears that the experimental data fitted the model fairly well and signified non-inclusion of insignificant terms. The "lack of fit F-value" of 8.16 implies that the lack of fit is not significant relative to the pure error. There is a $11.36 \%$ chance that a "lack of fit Fvalue" this large could occur due to noise.

In Figure 1, studentized residuals against predicted TOC removal percent is depicted and clearly indicates 


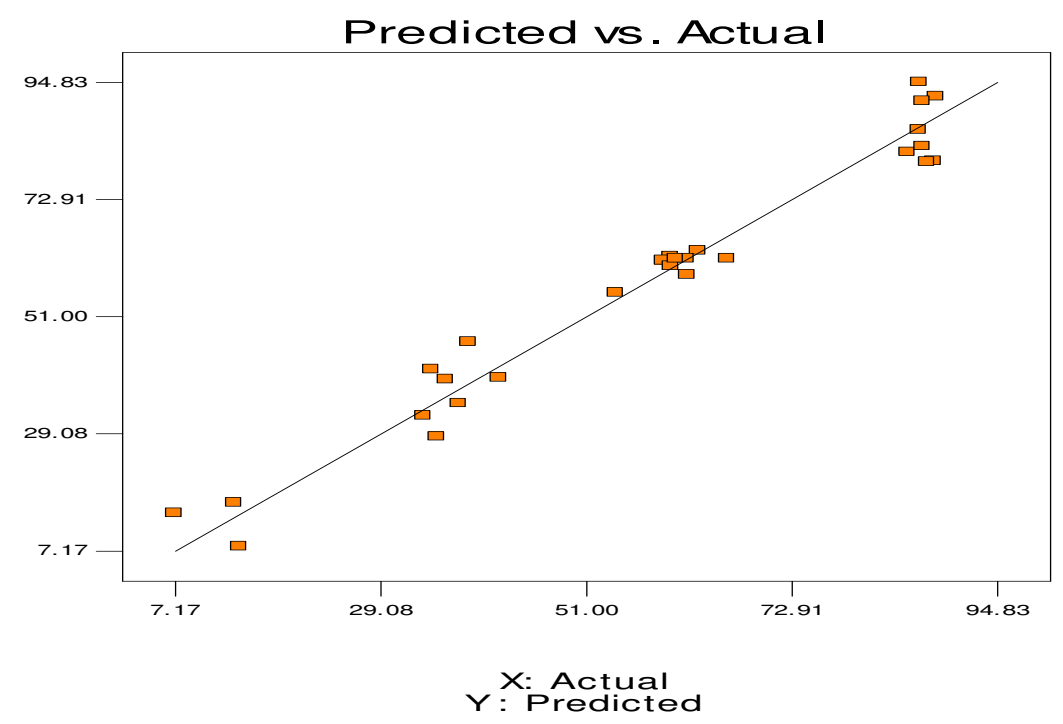

Figure 2. Plot of actual responses against predicted values of the TOC removal percent.

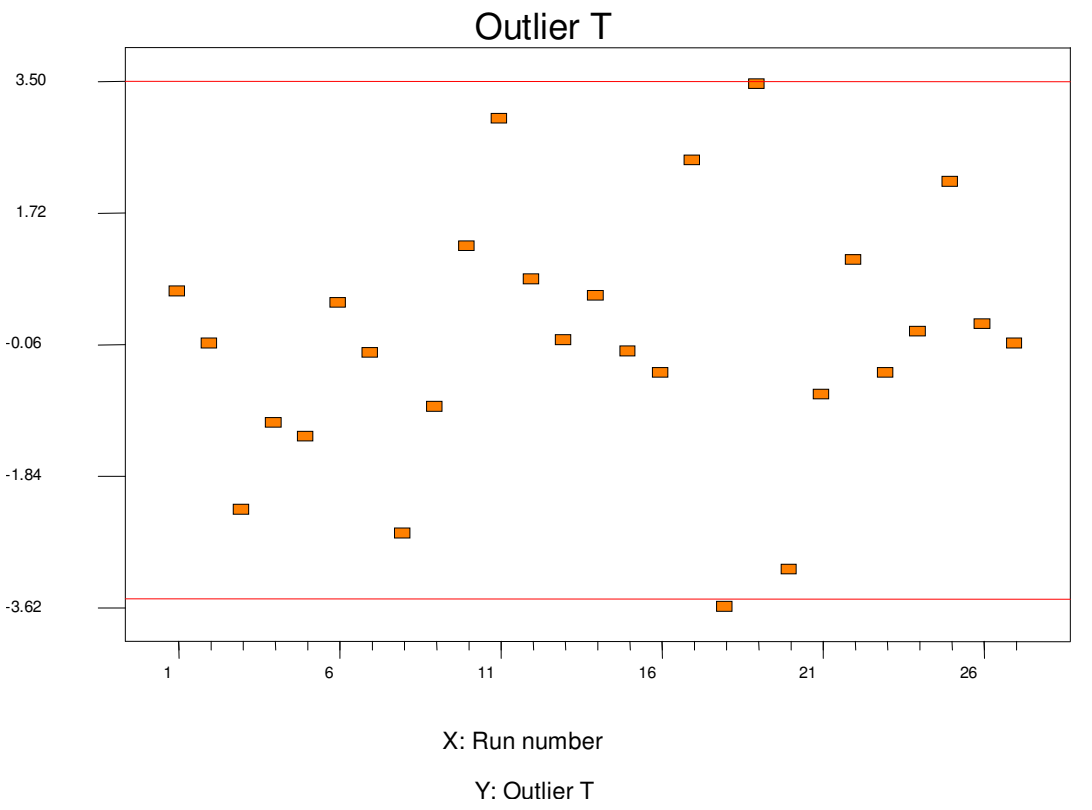

Figure 3. The outlier plot of the Fenton process for phenol mineralisation.

the lack of need for transformation. The random scattering of the points instead of funnel-shaped pattern sometimes observed suggest that, the variance of original observations to be a constant for all values of the response (Myers and Montgomery, 2002; Montgomery, 2009).

Experimentally determined responses (actual values) were plotted against responses obtained from the developed approximating function (predicted values) the plot (Figure 2) showed that, there is a good agreement between the two set of results thus, validating the model's reliability under the independent variables investigated.

Finally, the number of standard deviations of the actual value deviates from the predicted value was determined from the outlier plot (Figure 3) for the TOC removal percent. The outliers (data points that lied far away from the true regression line) need to be assessed as they can be used to determine data recording error or region of the independent factor variable space where the fitted model is a poor approximation to the true response surface (Montgomery, 2009). 


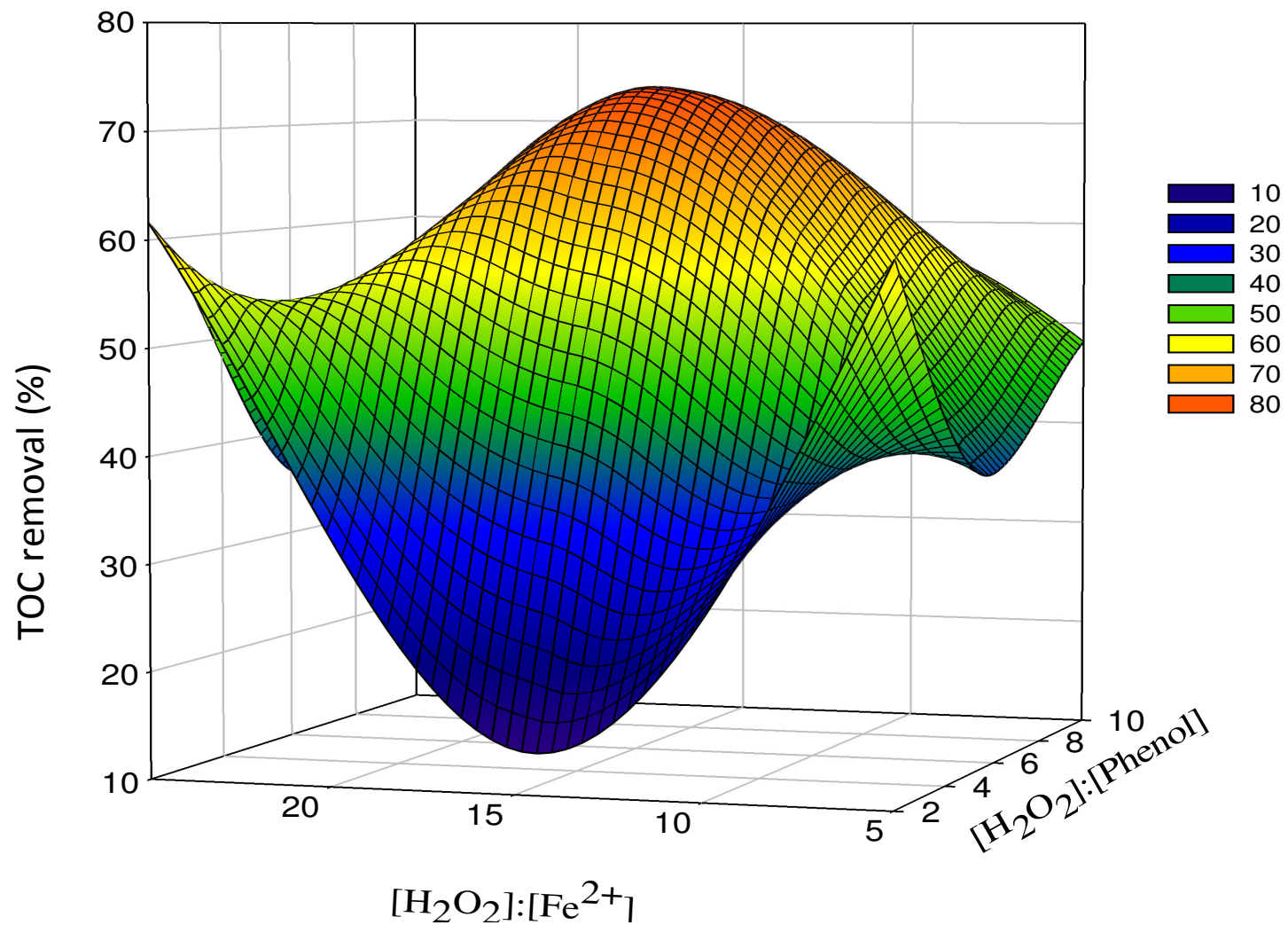

Figure 4. $3 \mathrm{D}$ response surface graph for phenol mineralisation at $\mathrm{pH}=3,\left[\mathrm{H}_{2} \mathrm{O}_{2}\right]:[$ Phenol $]=2$ to 10 and $\left[\mathrm{H}_{2} \mathrm{O}_{2}\right]:\left[\mathrm{Fe}^{2+}\right]=5$ to 25 .

Furthermore, the model equation was obtained using the least squares method, the slope and intercept which are sensitive to outliers thus, estimates of regression coefficients can be distorted. From the outlier plot, it is shown that all the standardized residual are within the range of \pm 3.50 interval. This shows that, the model approximation of the response surface was satisfactory and not associated with data recording error.

\section{Effect of independent variables on TOC \% removal}

The most common wastewater analysis index is COD reduction. However, it must be mentioned that the COD test is based on the assumption that all the organic materials can be oxidized by a strong oxidizing agent under acidic conditions. However, the COD test has some restrictions as detailed by Papadopoulos et al. (2007). Some aromatic compounds are not oxidized completely within the COD test procedure and thus, the oxygen demands obtained do not reflect the actual oxygen requirements for oxidation. Phenol containing effluents are one of such wastewater as they are aromatic and yield aromatic by products. Hence, TOC is the most suitable measure and a direct expression of the total organic content than COD.

\section{Effect of the ratios $\left[\mathrm{H}_{2} \mathrm{O}_{2}\right]$ : $\left[\right.$ Phenol] and $\left[\mathrm{H}_{2} \mathrm{O}_{2}\right]:\left[\mathrm{Fe}^{2+}\right]$}

Figure 4, depicts the response surface showing the interaction between two variables $\left(\left[\mathrm{H}_{2} \mathrm{O}_{2}\right]\right.$ : [phenol] and $\left.\left[\mathrm{H}_{2} \mathrm{O}_{2}\right]:\left[\mathrm{Fe}^{2+}\right]\right)$ at constant $\mathrm{pH}$ of 3.0 and over the whole concentration range considered. A semi spherical response surface was obtained with maximum TOC removal at the ratios of 6 and 15 for $\left[\mathrm{H}_{2} \mathrm{O}_{2}\right]$ : [phenol] and $\left[\mathrm{H}_{2} \mathrm{O}_{2}\right]:\left[\mathrm{Fe}^{2+}\right]$, respectively. Moreover, the significance of investigating the interaction of both parameters is clearly demonstrated. It is observed that at a ratio of 15 for $\left[\mathrm{H}_{2} \mathrm{O}_{2}\right]:\left[\mathrm{Fe}^{2+}\right]$ the optimal TOC reduction was attained. Here, oxidation reaction performed at a ratio of 2 $\left(\left[\mathrm{H}_{2} \mathrm{O}_{2}\right]:[\right.$ phenol] $)$ results in a sharp decrease in the system's performance.

The increase in TOC reduction with the increase in the ratio is as observed by Chakinala et al. (2008) and that the ratio increase favours the simultaneous generation of more. $\mathrm{OH}$ radical as a result of an increase in oxidant concentration. At the ratio of 15 for the parameter $\left[\mathrm{H}_{2} \mathrm{O}_{2}\right]:\left[\mathrm{Fe}^{2+}\right]$ sufficient $\mathrm{Fe}^{2+}$ species are available within the reaction mixture propelling more catalytic degradation of the oxidant.

High TOC reductions are observed at the edges of the matrix region, these are represented in experimental runs. However, when conducting the reaction at these 


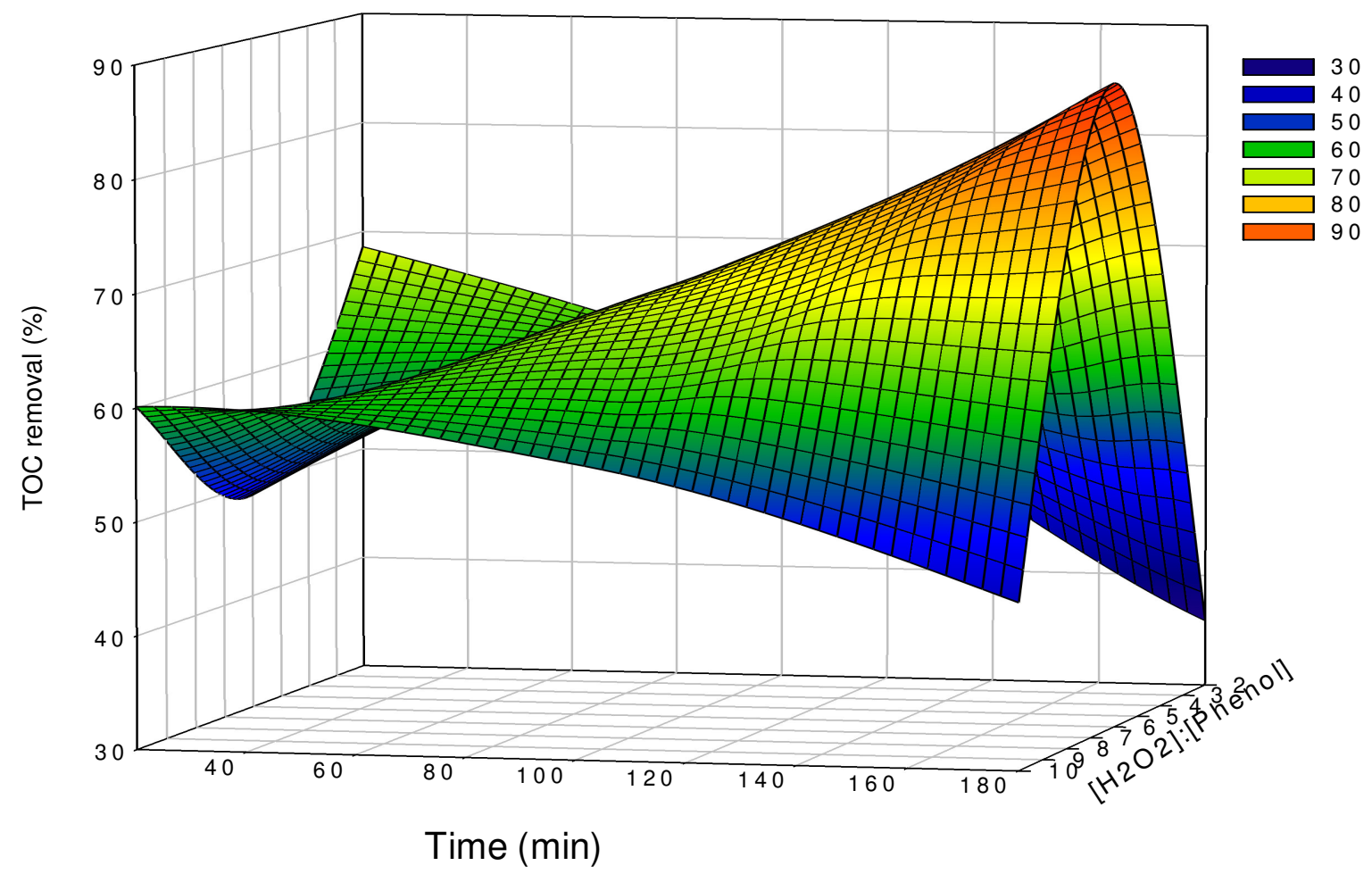

Figure 5. 3D response surface graph for phenol mineralisation at $\mathrm{pH}=3,\left[\mathrm{H}_{2} \mathrm{O}_{2}\right]:[$ Phenol $]=2$ to 10 and reaction time $=20$ to $180 \mathrm{~min}$.

conditions the $\mathrm{pH}$ of the reaction mixture should be monitored as a decrease in the $\mathrm{pH}$ can be anticipated. This is due to the carboxylic intermediate products generated from the degradation of phenol, which is acidic in nature (Kavitha and Palanivelu, 2004). This promotes the availability of excess $\mathrm{H}^{+}$as described earlier in materials and methods. Furthermore, reaction between 'OH and the $\mathrm{H}^{+}$is enhanced and thus, the system's efficiency might decrease (Kiril et al., 2010).

\section{Effect of reaction time and $\left[\mathrm{H}_{2} \mathrm{O}_{2}\right]$ :[Phenol] ratio}

The 3D interactive effect of reaction time and $\left[\mathrm{H}_{2} \mathrm{O}_{2}\right]$ :[Phenol] of the whole concentration is shown in Figure 5. It is seen that the TOC percent removal increased with an increase in the ratio $\left[\mathrm{H}_{2} \mathrm{O}_{2}\right]$ : $[$ Phenol] with the optimal obtained at the maximal oxidation time. The ratio earlier observed for the ratio was found to be maintained with respect to time also. The TOC reduction was found to increase with increase in the ratio up to 6 after which the efficiency decreased. The lower after the optimum ratio are consequences of the radical reactions described earlier.

Percent TOC removal for $\left[\mathrm{H}_{2} \mathrm{O}_{2}\right]$ :[phenol] increased considerably and rapidly for the values investigated. The exceptions are the ratio of 2 and 10 at reaction times of approximately $20 \mathrm{~min}$. At these conditions, oxidant concentration was sufficient from the onset to mineralise the phenol within the first $20 \mathrm{~min}$. From the contour plot in Figure 6, it would be seen that ratios lower than 6 for $\left[\mathrm{H}_{2} \mathrm{O}_{2}\right]$ :[phenol] do not favour the TOC removal likewise above a ratio of 8 . For $\left[\mathrm{H}_{2} \mathrm{O}_{2}\right]$ : $[$ Phenol] ratio, the optimal is seen to be located around the value of 15 . It is thus, evidently clear that the peroxidation reaction within the range of 6 to 8 significantly resulted in a TOC removal increase from a 60 to almost $90 \%$ when treated at a ratio of 15 .

The mineralization of the aqueous phenol solution fitted the experimental and predicted data fairly well. The quadratic terms in the equation are due to the strong influence of the regressors on the coefficients and the response graphically depicted by the surface response curve in Figure 4.

The significance of the ratio $\left[\mathrm{H}_{2} \mathrm{O}_{2}\right]:[$ phenol] is vividly seen from the equation as higher values positively influenced the response, this is also supported by the high values observed from the interaction coefficient of the ratio with time.

\section{Oxidant to catalyst mass ratio, $\left[\mathrm{H}_{2} \mathrm{O}_{2}\right]:\left[\mathrm{Fe}^{2+}\right]$}

As observed by Benatti et al. (2006), the ratio of $\left[\mathrm{H}_{2} \mathrm{O}_{2}\right]:\left[\mathrm{Fe}^{2+}\right]$ is a crucial factor that determines the degradation efficiency. All the variables studied are known to 


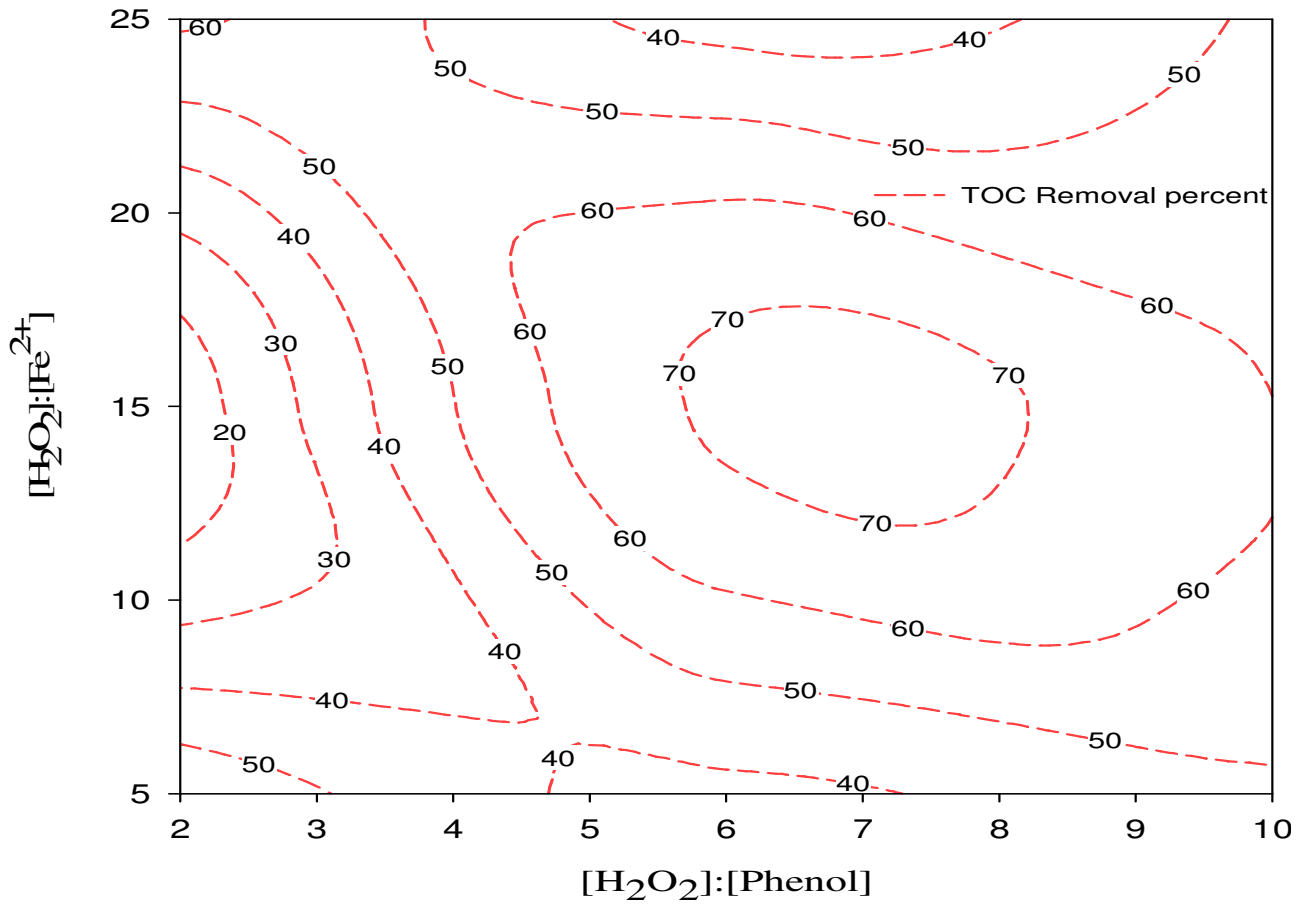

Figure 6. Contour plot for phenol mineralisation at $\mathrm{pH}=3,\left[\mathrm{H}_{2} \mathrm{O}_{2}\right]:[$ Phenol $]=2$ to 10 and $\left[\mathrm{H}_{2} \mathrm{O}_{2}\right]:\left[\mathrm{Fe}^{2+}\right]=5$ to 25 .

interact strongly and the overall process efficacy relies on attaining a balance in quantities of both the Fenton's reagents used in relation to the strength of the organic contamination. For the $\left[\mathrm{H}_{2} \mathrm{O}_{2}\right]$, it is of uttermost importance to introduce just enough amounts that would sustain the reaction to completion not only because excess contributes to COD, but also the adverse effect of the excess to microorganisms when eventually discharged (Chakinala et al., 2008). It is therefore imperative to determine an optimum ratio at which to attain maximal TOC removal and consume the reagents.

The required catalyst necessary to catalyses the decomposition of the oxidant was computed based on the required oxidant concentration needed to oxidize the phenol solution. Thereafter, the mass ratio of the oxidant and catalyst was varied as described in several literatures. The ranges of values used in this study were chosen to fall within the reported limits (Benatti et al., 2006; Martins et al., 2010; Martins et al., 2005).

Several authors have worked with molar ratio as the basis for establishing the ratios mass ratios $\left[\mathrm{H}_{2} \mathrm{O}_{2}\right]$ :[phenol] and $\left[\mathrm{H}_{2} \mathrm{O}_{2}\right]:\left[\mathrm{Fe}^{2+}\right]$. However, recent studies report use of mass of reagents instead of molar concentration (Martins et al., 2005; Benatti et al., 2006; Martins et al., 2010; Bach et al., 2010). We thus, adopted the mass approach to determine the necessary amounts of the reagents that would maintain the ratio of the designed matrix (Table 1).

From the plot of Figure 7, it is evident that the ratio of 15 is the optimal. This condition is furthermore, concurred with the $3 D$ response surface and contour plots in Figures 4 and 6, respectively. At ratios above 15, possible scavenging reactions of the generated radicals with less reactive hydroperoxyl radicals between the $\cdot \mathrm{OH}$ radicals themselves or the oxidant and $\cdot \mathrm{OH}$ radical might occur (Kavitha and Palanivelu, 2004) as shown in Equations (5) to (7):

$$
\begin{gathered}
\mathrm{H}_{2} \mathrm{O}_{2}+{ }^{\circ} \mathrm{OH} \rightarrow \mathrm{H}_{2} \mathrm{O}+\mathrm{HO}_{2}{ }^{\circ} \\
\mathrm{HO}_{2}{ }^{\circ}+\mathrm{OH} \rightarrow \mathrm{H}_{2} \mathrm{O}+\mathrm{O}_{2}
\end{gathered}
$$

${ }^{\circ} \mathrm{OH}+{ }^{\circ} \mathrm{OH} \rightarrow \mathrm{H}_{2} \mathrm{O}_{2}$

Contribution to the scavenging of the ${ }^{\circ} \mathrm{OH}$ radicals have also been reported by Bouasla et al. (2010) and represented by equation (8):

$$
\mathrm{Fe}^{2+}+{ }^{\circ} \mathrm{OH} \rightarrow \mathrm{Fe}^{3+}+\mathrm{HO}^{-}
$$

\section{Initial phenol concentration}

The design matrix dictates three initial phenol concentrations and from Figure 8 of the contour's plot, the process was more effective in TOC removal at a lower concentration. As seen from the plot, TOC removal 


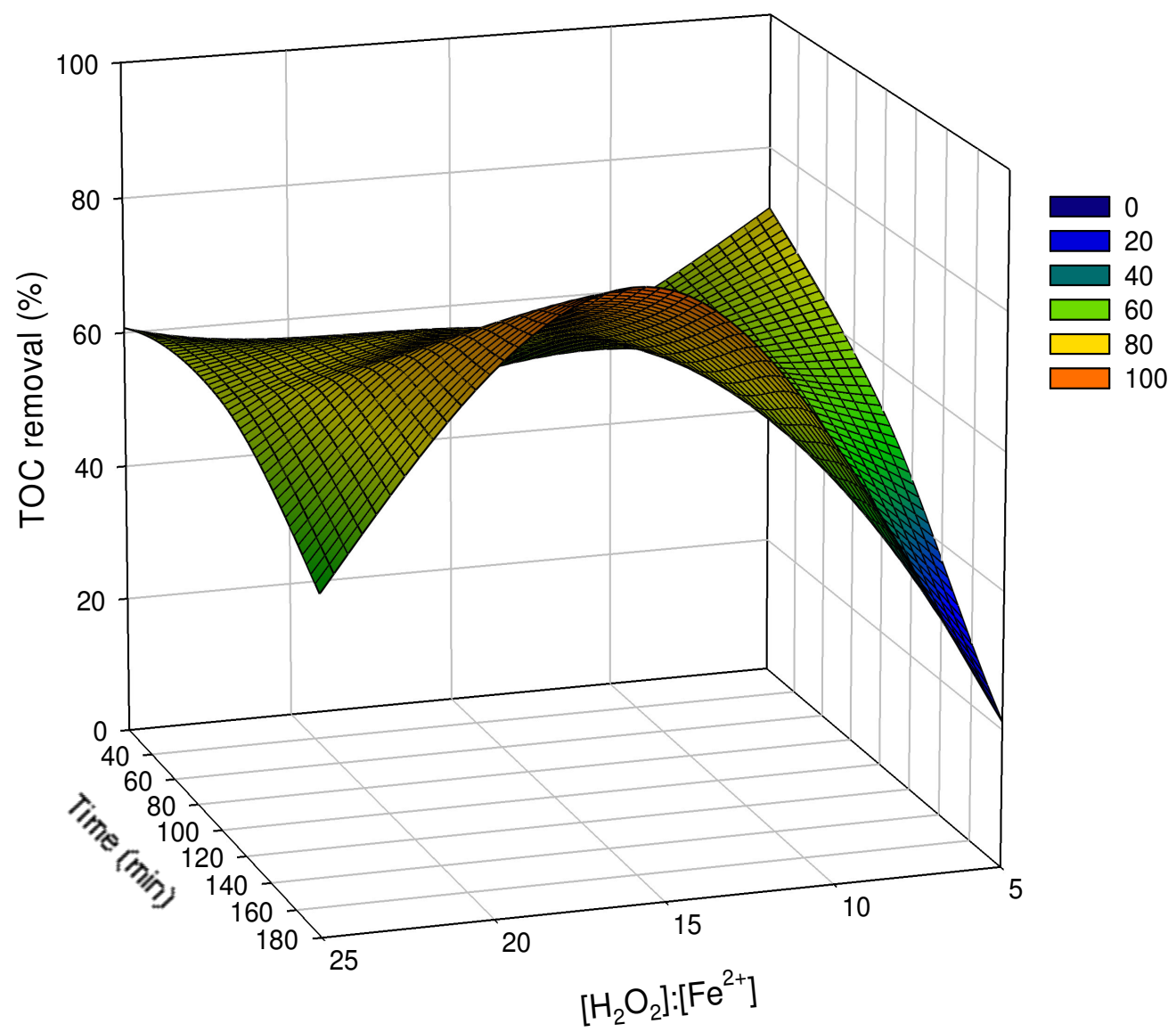

Figure 7. $3 \mathrm{D}$ response surface graph for phenol mineralisation at $\mathrm{pH}=3,\left[\mathrm{H}_{2} \mathrm{O}_{2}\right]:\left[\mathrm{Fe}^{2+}\right]=2$ to 10 and reaction time $=20$ to $180 \mathrm{~min}$.

slightly decreased with an increase in reaction time and concentrations. The maximum phenol TOC removals at the end of the oxidation reaction time were $88.4(20 \mathrm{~min})$, 66.1 (100 $\mathrm{min}$ ) and $41.8 \%$ (180 $\mathrm{min})$ for $5,52.5$ and 100 $\mathrm{mg} / \mathrm{l}$, respectively. From Table 1, the ratios corresponding to these were 2 and 5,10 and 25 and 10 and 25 $\left[\mathrm{H}_{2} \mathrm{O}_{2}\right]$ :[phenol] and $\left[\mathrm{H}_{2} \mathrm{O}_{2}\right]:\left[\mathrm{Fe}^{2+}\right]$, respectively. However, relatively similar TOC reductions are equally obtained at a lower reaction time of $20 \mathrm{~min}$ for the 52.5 and $100 \mathrm{mg} / \mathrm{l}$ concentrations. These are the runs $3(34.5 \%)$ and 16 $(60.1 \%)$ at the following conditions: 6 and 15, and 10 and 15 for $\left[\mathrm{H}_{2} \mathrm{O}_{2}\right]:\left[\right.$ phenol] and $\left[\mathrm{H}_{2} \mathrm{O}_{2}\right]:\left[\mathrm{Fe}^{2+}\right]$ ratios, respectively.

From Figure 8, it is seen that mineralization is favoured with the increase in concentration and for all the phenol concentrations the optimal mineralization could be attained within the first $20 \mathrm{~min}$. This implies that at the process conditions investigated, ${ }^{\circ} \mathrm{OH}$ formation and its consumption were favoured with a decrease in concentration as observed by Lopez et al. (2005). This led to the rapid rate of reaction recorded and clearly indicated limitations of the $\mathrm{H}_{2} \mathrm{O}_{2}$ at a higher concentration. For effective TOC removal at such concentrations, the ratio $\left[\mathrm{H}_{2} \mathrm{O}_{2}\right]$ : [phenol] should be higher than the currently studied limits of 10 .

\section{Individual effect of (phenol)o with reaction time}

The trend depicted by the treatment at different oxidation times varied with initial concentration of the phenol solution (Figure 9). Clearly, a reaction time of $20 \mathrm{~min}$ is sufficient to mineralise approximately 40,70 and $90 \%$ of the phenol. At a reaction time of $20 \mathrm{~min}$, rapid $\cdot \mathrm{OH}$ attack to the phenolic aromatic ring resulted in the greater TOC removal percentages recorded. Thus, increase in reaction time beyond 20 min decreases the efficiency of the process in treating wastewater containing phenol at such concentrations and at the operating conditions reported in this study.

The TOC reduction for the three concentrations with respect to time is presented in Figure 9. The reduction ranged from 7.2 to $41.8,59.3$ to 66.1 and 38.6 to $88.4 \%$ for $100,52.5$ and $5 \mathrm{mg} / \mathrm{l}$ initial phenol concentrations. The decrease in TOC reduction is directly related to competing for and consumption of the generated $\cdot \mathrm{OH}$ by 


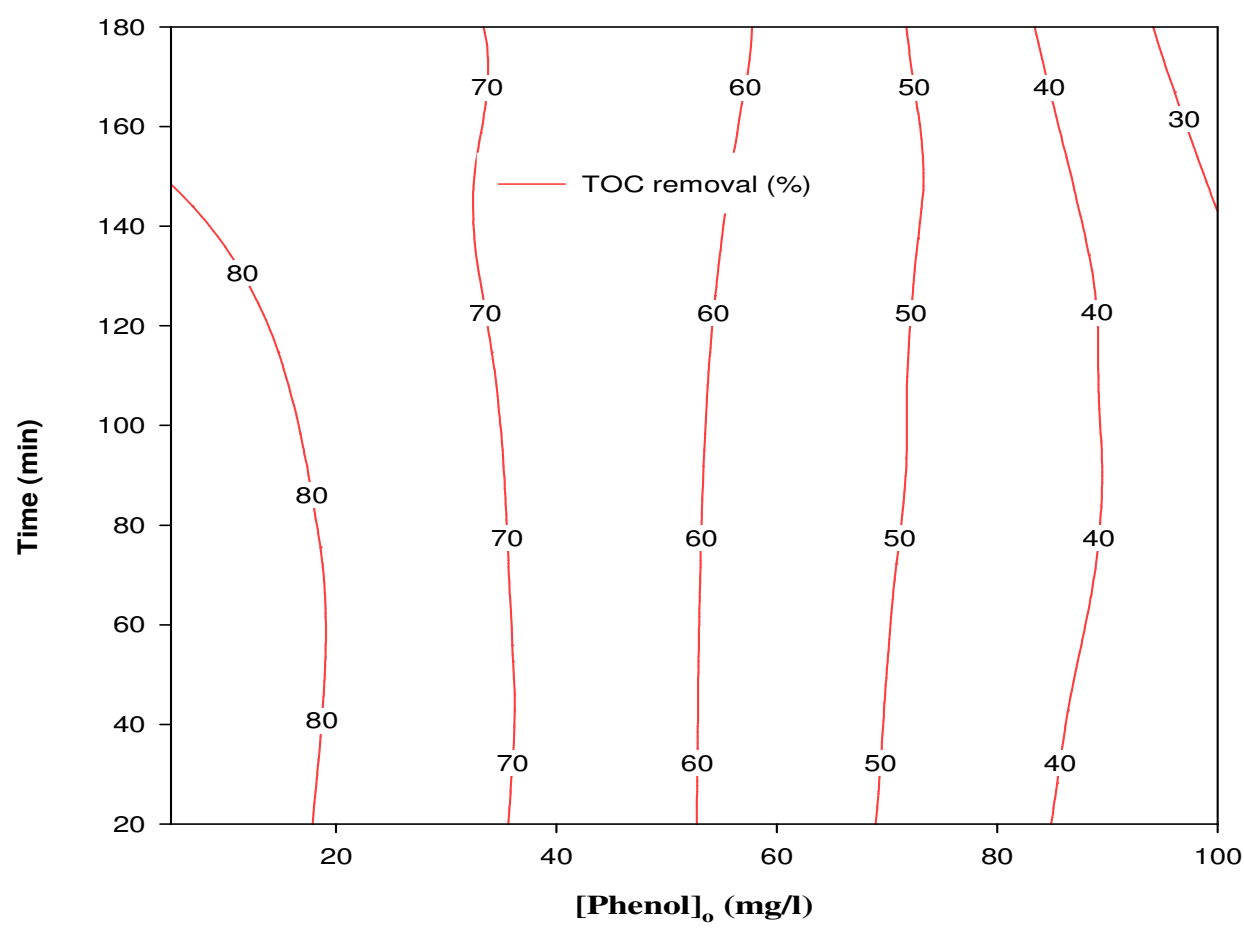

Figure 8. Contour plot for phenol mineralisation at $\mathrm{pH}=3,\left[\mathrm{H}_{2} \mathrm{O}_{2}\right]:[$ Phenol $]=2$ to 10 and $\left[\mathrm{H}_{2} \mathrm{O}_{2}\right]:\left[\mathrm{Fe}^{2+}\right]=5$ to 25 .

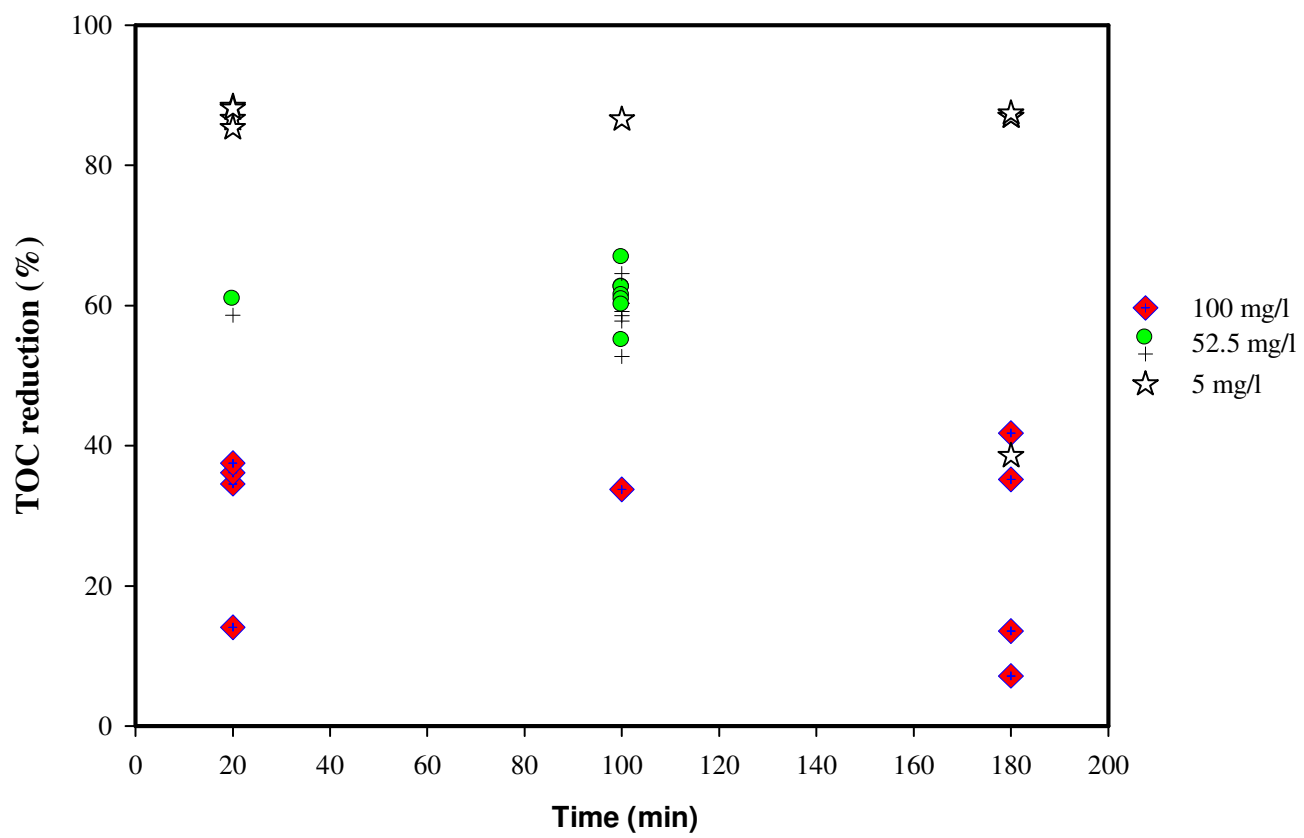

Figure 9. Plot of phenol \% TOC reduction for [Phenol $]_{\circ}=5,52.2$ and $100 \mathrm{mg} / \mathrm{l}$. Reaction time $=20$ to 180 at $\mathrm{pH}=3$.

more organic radical associated with higher phenol concentrations. This strongly indicates that initial concentration had a significant effect on the degradation of the phenol.
For the $5 \mathrm{mg} / \mathrm{l}$ initial phenol concentrations, results showed an increase in reaction time did results in appreciable TOC reduction thus, not time sensitive. Except for the run at 20 which yielded $38.6 \%$ after $180 \mathrm{~min}$ 
of reaction time; all the other runs ranged between 85.3 and $88.4 \%$. As the highest ratio was employed, the low efficiency could be associated with excess $\mathrm{H}_{2} \mathrm{O}_{2}$ available in the system which retarded the Fenton process. It has been shown that, the $\mathrm{OH}$ radicals are trapped by the excess $\mathrm{H}_{2} \mathrm{O}_{2}$ molecules leading to the earlier described scavenging reactions (5) to (7) (Kavitha and Palanivelu, 2004).

Generally, the reagents consumption ranged from 0.003 to $0.1802 \mathrm{ml}$ of $30 \mathrm{w} / \mathrm{w} \% \mathrm{H}_{2} \mathrm{O}_{2}$ and 0.008 to $4 \mathrm{ml}$ for $\mathrm{Fe}^{2+}$. The concentration of the $\mathrm{Fe}^{2+}$ varied between 0.04 and $12 \mathrm{mg} / \mathrm{l}$. On the reagent utilisation, specifically and at the optimal conditions the following was recorded: (1) $(\text { Phenol })_{0}=100 \mathrm{mg} / \mathrm{l} ; \mathrm{H}_{2} \mathrm{O}_{2}=0.1802 \mathrm{ml}$ and $\mathrm{Fe}^{2+}=0.8$ $\mathrm{ml}(4 \mathrm{mg} / \mathrm{l})$, (2) $(\text { Phenol })_{0}=52.5 \mathrm{mg} / \mathrm{l} ; \mathrm{H}_{2} \mathrm{O}_{2}=0.1517 \mathrm{ml}$ and $\mathrm{Fe}^{2+}=0.7 \mathrm{ml}(3.5 \mathrm{mg} / \mathrm{l})$ and $(3)(\text { Phenol })_{0}=52.5$ $\mathrm{mg} / \mathrm{l} ; \mathrm{H}_{2} \mathrm{O}_{2}=0.1517 \mathrm{ml}$ and $\mathrm{Fe}^{2+}=0.7 \mathrm{ml}(3.5 \mathrm{mg} / \mathrm{l})$. It is evident that less reagents were employed introduced into the system.

\section{Comparison with similar works on phenol mineralization}

The main merit of advanced oxidation is its potentials for mineralizing effluent and the indices determining this parameter is the TOC values. Comparatively values of degradation (COD) are higher than mineralization (TOC). As Bach et al. (2010) highlighted, high COD values do not necessarily signify completion of the oxidation reaction or removal efficiencies. Thus, the comparison of the AOP was limited to works reporting mineralization.

Mostly reported mineralization rates of phenol are less than $60 \%$, for example, Kavitha and Palanivelu (2004), achieved $41 \%$ mineralization for the unassisted Fenton method after 2 h. Hermosilla et al. (2009) reported a reduction of about $80 \%$ in TOC in their photo-Fenton treatment. Lurascu et al. (2009) degraded and mineralized phenol using an immobilized heterogeneous photo-Fenton catalyst, a near total conversion of the phenol at $1 \mathrm{mmol} / \mathrm{l}$ concentration was achieved. However, the process was costly as it involved use of oxidant, heating at elevated temperatures to prepare the catalyst and use of UV source for the irradiation. Yalfani et al. (2009) reported 58\% mineralization using the conventional Fenton process and modified the process by generating the hydrogen peroxide in situ using oxygen and formic acid; they obtained almost complete destruction of phenol at a reaction time of $360 \mathrm{~min}$ with nearly $60 \%$ TOC removal.

Structurally, phenol is a cyclic compound consisting of six and five member rings, thus, the energy requirement for breaking this cycle is much higher relative to single chain as the former is less reactive and more stable than single-chained compounds (Annadurai et al., 2008). In the open scientific literature, works on combined Fenton's reagent treatments with other techniques are abundant.
For example, Chakinala et al. (2008) reported combined hydrodynamic cavitation and heterogeneous advanced Fenton's processing for phenol mineralization in a multivariate design, the maximum TOC removal after a reaction time of 105 min using the modified AFP was 50 to $60 \%$.

Other AOP's conversion of phenol was low when using low-pressure UV lamps, for example, Hosseini et al. (2007) reported a maximum of $52.7 \%$ conversion with 80 $\mathrm{W}$ lamps over a reaction time of $240 \mathrm{~min}$. Though they achieved higher conversion but employed a $125 \mathrm{~W}$ UV lamp. Similarly, 40 and $80 \mathrm{mg} / \mathrm{l}$ phenol was decomposed by the photocatalytic treatment in $6 \mathrm{~h}$ (Augugliaro et al., 1988) and $8 \mathrm{~h}$ (Sivalingam et al., 2004), respectively. Comparison of researches that considered same reaction time of 180 min achieved $50 \%$ (Hosseini et al., 2007) and 25\% (Carpio et al., 2005) TOC removal. Suryaman et al. (2006) mineralized $50 \mathrm{mg} / \mathrm{l}$ phenol, although 98\% TOC removal was achieved, but it required $30 \mathrm{~min}$ of an AOP (photocatalytic process) coupled with $10.5 \mathrm{~h}$ of biological treatment.

From the aforementioned researches compared, it is evident that mineralizing phenol based on conditions of our findings is more attractive than most reported TOC removal percentages. Arguably, some works apparently achieved a better result than present work. However, as highlighted earlier their process methodology was capital intensive, required elaborate design and setting, maintenance cost, which would offset the marginal benefit.

\section{Conclusions}

Response surface methodology was successfully used in optimizing the mineralization parameters for a phenol solution at concentrations ranging from 5 to $100 \mathrm{mg} / \mathrm{l}$ by Fenton oxidization method. An approximating model equation was developed that adequately described the mineralization process. Based on residual analysis, the suitability of the model was found to be satisfactory. Also, data generated from the quadratic polynomial fitted the response surface well with correlation coefficient values of 0.9663 and 0.9689 for $R^{2}$ and $R_{\text {adj }}^{2}$, respectively.

The mineralization was effectively achieved within 20 min for the range of concentrations investigated. The optimum conditions for the process are ratios of 6 and 15 for $\left[\mathrm{H}_{2} \mathrm{O}_{2}\right]:\left[\right.$ phenol] and $\left[\mathrm{H}_{2} \mathrm{O}_{2}\right]:\left[\mathrm{Fe}^{2+}\right]$, respectively. The maximum Total Organic Carbon (TOC) reduction was $88.4 \%$.

The findings of the study show fast reaction rate and low reagents consumption. This is seen in the case of optimal conditions for: (1) $(\text { Phenol })_{0}=100 \mathrm{mg} / \mathrm{l} ; \mathrm{H}_{2} \mathrm{O}_{2}=$ $0.1802 \mathrm{ml}$ and $\mathrm{Fe}^{2+}=0.8 \mathrm{ml}(4 \mathrm{mg} / \mathrm{l})$, (2) $(\text { Phenol })_{0}=$ $52.5 \mathrm{mg} / \mathrm{l} ; \mathrm{H}_{2} \mathrm{O}_{2}=0.1517 \mathrm{ml}$ and $\mathrm{Fe}^{2+}=0.7 \mathrm{ml}(3.5 \mathrm{mg} / \mathrm{l})$ and (3) $(\text { Phenol })_{0}=52.5 \mathrm{mg} / \mathrm{l} ; \mathrm{H}_{2} \mathrm{O}_{2}=0.1517 \mathrm{ml}$ and $\mathrm{Fe}^{2+}$ $=0.7 \mathrm{ml}(3.5 \mathrm{mg} / \mathrm{l})$. 
The study further asserted effectiveness of the conventional Fenton treatment technique in wastewater treatment. Furthermore, conducting the phenol mineralization at the experimental conditions negates the need for post treatment step necessary to reduce total iron ions, as $85 \%$ of the treated samples conformed to the minimum discharge levels. However, further work using industrial effluents known to contain myriad of contaminants and compounds with potential for consuming the radicals generated can be undertaken. Such studies would give an insight on wastewater containing radical scavengers such as chlorides and sulfides, for example, petroleum refinery effluents (PRE).

\section{REFERENCES}

Ahmadi M, Vahabzadeh F, Bonakdarpour B, Mofarrah E, Mehranian M (2005). Application of the central composite design and response surface methodology to the advanced treatment of olive oil processing wastewater using Fenton's peroxidation. J. Hazard. Mater. 123: 187-195.

Annadurai G, Ling LY, Lee JF (2008). Statistical optimization of medium components and growth conditions by response surface methodology to enhance phenol degradation by Pseudomonas putida. J. Hazard. Mater. 151: 171-178.

Augugliaro V, Palmisano L, Sclafani A, Minero C, Pelizzetti E (1988). Photocatalytic degradation of phenol in aqueous titanium dioxide dispersions Toxic \& Environ Chem. Pp: 89-109.

Ay F, Catalkaya EC, Kargi F (2009). A statistical experiment design approach for advanced oxidation of Direct Red azo-dye by photoFenton treatment. J. Hazard. Mater. 162: 230-236.

Bach A, Shemer H, Semiat R (2010) Kinetics of phenol mineralization by Fenton-like oxidation Desalination doi:10.1016/j. desal. 2010.04.011.

Banerjee A, Ghoshal AK (2005). Phenol degradation by Bacillus cereus: Pathway and kinetic modelling. Bioresour. Technol. 101: 5501-5507.

Barros AL, Pizzolato TM, Carissimi E, Schneider IAH (2006). Decolorizing dye wastewater from the agate industry with Fenton oxidation process. Miner. Eng. 19: 87-90.

Benatti CT, Tavares CRG, Guedes TA (2006). Optimization of Fenton's oxidation of chemical laboratory wastewaters using the response surface methodology. J. Environ. Manage. 80: 66-74.

Bouasla C, Samar ME-H, Ismail F (2010) Degradation of methyl violet $6 \mathrm{~B}$ dye by the Fenton process, Desalination 254: 35-41.

Busca G, Berardinelli S, Resini C, Arrighi L (2008). Technologies for the removal of phenol from fluid streams: A short review of recent developments. J. Hazard. Mater. 160: 265-288.

Cai W, Li J, Zhang Z (2007). The characteristics and mechanisms of phenol biodegradation by Fusarium sp. J. Hazard. Mater. 148: 38-42.

Carpio E, Zúñiga P, Ponce S, Solis J, Rodriguez J, Estrada W (2005). Photocatalytic degradation of phenol using $\mathrm{TiO}_{2}$ nanocrystals supported on activated carbon. J. Mol. Catal A: Chem. 228: 293-298.

Chakinala AG, Bremner DH, Gogate PR, Namkung K-C, Burgess AE (2008). Multivariate analysis of phenol mineralisation by combined hydrodynamic cavitation and heterogeneous advanced Fenton processing. Appl. Catal B Environ. 78: 11-18.

Chen Y, Chen Z, Xiao S, Liu H (2008). A novel thermal degradation mechanism of phenol-formaldehyde type resins. Thermochimica Acta 476: $39-43$.

Doan HD, Weli A, Wu J (2009). A combined photocatalytic and electrochemical treatment of wastewater containing propylene glycol methyl ether and metal ions. Chem. Eng. J. 151: 51-58.

Gernjak W, Krutzler T, Glaser A, Malato S, Caceres J, Bauer R, Fernandez-Alba AR (2003) Photo-Fenton treatment of water containing natural phenolic pollutants. Chemosphere. 50: 71-78.

Gonzalez G, Herrera G, Garcia MT, Pena MM (2001). Biodegradation of phenolic industrial wastewater in a fluidized bed bioreactor with immobilized cells of Pseudomonas putida. Bioresour. Technol. 80: 137-142.

Guo J, Al-Dahhan M (2005). Catalytic wet air oxidation of phenol in concurrent downflowand upflow packed-bed reactors over pillared clay catalyst. Chem. Eng. Sci. 60: 735-746.

Hermosilla D, Cortijo M, Huang CP (2009). The role of iron on the degradation and mineralization of organic compounds using conventional Fenton and photo-Fenton processes. Chem. Eng. J. 155: 637-646.

Hong S-S, Ju C-S, Lim C-G, Ahn B-H, Lim K-T, Lee G-D (2001). A photocatalytic degradation of phenol over $\mathrm{TiO}_{2}$ prepared by sol-gel method. J. Ind. Eng. Chem. 7: 99-104.

Hosseini SN, Borghei SM, Vossoughi M, Taghavinia N (2007). Immobilization of $\mathrm{TiO}_{2}$ on perlite granules for photocatalytic degradation of phenol. Appl. Catal B Environ. 74: 53-62.

lurascu B, Siminiceanu I, Vione D, Vicente MA, Gil A (2009). Phenol degradation in water through a heterogeneous photo-Fenton process catalyzed by Fe-treated laponite. Water Res. 43: 1313-1322.

Kavitha V, Palanivelu K (2004). The role of ferrous ion in Fenton and photo-Fenton processes for the degradation of phenol. Chemosphere 55: $1235-1243$.

Kiril MB, Yonar T, Yalili Kiliç M, Kestioglu K (2010). Pre-treatment studies on olive oil mill effluent using physicochemical Fenton and Fenton-like oxidations processes. J. Hazard. Mater. 174: 122-128.

Li X-y, Cui Y-h, Feng Y-j, Xie Z-m, Gu J-D (2005). Reaction pathways and mechanisms of the electrochemical degradation of phenol on different electrodes. Water Res. 39: 1972-1981.

Lopez A, Mascolo G, Detomaso A, Lovecchio G, Villani G (2005). Temperature activated degradation (mineralization) of 4-chloro-3methyl phenol by Fenton's reagent. Chemosphere 59: 397-403.

Mahiroglu A, Tarlan-Yel E, Sevimli MF (2009). Treatment of combined acid mine drainage (AMD) - Flotation circuit effluents from copper mine via Fenton's process. J. Hazard. Mater. 166: 782-787.

Martins AF, Vasconcelos TG, Wilde ML (2005). Influence of variables of the combined coagulation-Fenton-sedimentation process in the treatment of trifluraline effluent. J. Hazard. Mater. 127: 111-119.

Martins RC, Rossi AF, Quinta-Ferreira RM (2010). Fenton's oxidation process for phenolic wastewater remediation and biodegradability enhancement. J. Hazard. Mater. 180:716-721.

Montgomery DC (2009). Design and Analysis of Experiments. $7^{\text {th }}$ edition, John Wiley and Sons, New York.

Moussavi G, Barikbin B, Mahmoudi M (2010). The removal of high concentrations of phenol from saline wastewater using aerobic granular SBR. Chem. Eng. J. 158: 498-504.

Myers RH, Montgomery DC (2002). Response Surface Methodology: Process and Product Optimization Using Designed Experiments. $2^{\text {nd }}$ ed., Wiley, New York.

Papadopoulos AE , Fatta D, Loizidou M (2007). Development and optimization of dark Fenton oxidation for the treatment of textile wastewaters with high organic load, J. Hazard. Mater. 146: 558-563.

Pontes RFF, Moraes JEF, Machulek A(Jr), Pinto JM (2010). A mechanistic kinetic model for phenol degradation by the Fenton process. J. Hazard. Mater. 176: 402-413.

Prieto MB, Hidalgo A, Serra JL, Llama MJ (2002). Degradation of phenol by Rhodococcus erythropolis UPV-1 immobilized on Biolite in a packed bed reactor. J. Biotechnol. 97: 1-11.

Priya SS, Premalatha M, Anantharaman N (2008). Solar photocatalytic treatment of phenolic wastewater-potential challenges and opportunities. ARPN J. Eng. Appl. Sci. 3: 36-41.

Salamatinia B, Mootabadi H, Bhatia S, Abdullah AZ (2010). Optimization of ultrasonic-assisted heterogeneous biodiesel production from palm oil: A response surface methodology approach. Fuel Proces. Technol. 91: 441-448.

Sivalingam GP, Priya MH, Madras G (2004). Kinetic of the photodegradation of substituted phenols by solution combustion synthesized $\mathrm{TiO}_{2}$. Appl. Catal B Environ. 51: 67-76.

Suryaman D, Hasegawa K, Kagaya S (2006). Combined biological and photocatalytic treatment for the mineralization of phenol in water. Chemosphere, 65: 2502-2506.

Tarley CRT, Silveira G, dos Santos WNL, Matos GD, da Silva EGP, Bezerra MA, Miró M, Ferreira SLC (2009). Chemometric tools in electro analytical chemistry: Methods for optimization based on 
factorial design and response surface methodology. Microchem. J. 92: 58-67.

Tekin H, Bilkay O, Ataberk SS, Balta TH, Ceribasi IH, Sanin FD, Dilek FB, Yetis $U$ (2006). Use of Fenton oxidation to improve the biodegradability of a pharmaceutical wastewater. J. Hazard. Mater. 136: 258-265.

Virkutyte J, Rokhina E, Jegatheesan V (2010). Optimisation of ElectroFenton denitrification of a model wastewater using a response surface methodology. Bioresour. Technol. 101: 1440-1446.

Wei Y, Van Houten RT, Borger AR, Eikelboom DH, Fan Y (2003). Minimization of excess sludge production for biological wastewater treatment. Water Res. 37: 4453-4467.
Yalfani MS, Contreras S, Medina F, Sueiras J (2009). Phenol degradation by Fenton's process using catalytic in situ generated hydrogen peroxide. Appl. Catal B Environ. 89: 519-526.

Yang S, Zhu W, Wang J, Chen Z (2008). Catalytic wet air oxidation of phenol over $\mathrm{CeO}_{2}-\mathrm{TiO}_{2}$ catalyst in the batch reactor and the packedbed reactor. J. Hazard. Mater. 153: 1248-1253. 